\title{
The flow of forage particles and solutes through segments of the digestive tracts of cattle*
}

\author{
M. J. Wylie ${ }^{1}$, W. C. Ellis ${ }^{1} \dagger$, J. H. Matis ${ }^{2}$, E. M. Bailey ${ }^{3}$, W. D. James ${ }^{4}$ and D. E. Beever ${ }^{5}$ \\ ${ }^{1}$ Department of Animal Science, ${ }^{2}$ Department of Statistics, ${ }^{3}$ Department of Veterinary Physiology and Pharmacology and \\ ${ }^{4}$ Center for Chemical Characterization and Analysis, Chemistry Department, Texas A \& M University, College Station, \\ Texas 77843 USA \\ ${ }^{5}$ Department of Agriculture, University of Reading, Earley Gate, Reading RG6 6AT, UK
}

(Received 19 October 1998 - Revised 1 June 1999 - Accepted 16 August 1999)

\begin{abstract}
An experiment was conducted to investigate the compartmental mean residence time, (CMRT) of feed residues in segments of gastrointestinal digesta of mature Holstein steers. The objective was to evaluate assumptions that feed residues flow through ruminal digesta as sequential mixing pools having age-dependent (GN) and age-independent (G1) distributed residence times respectively (GN $\rightarrow$ G1 flow). The basal diet was a semi-tropical hay containing $98 \mathrm{~g}$ crude protein and $503 \mathrm{~g}$ apparently digestible DM per $\mathrm{kg}$ DM. The hay was consumed and feed residues of different size and/or previous digestion from the hay were inserted into the reticulo-rumen (rumen) and abomasum. Marker profiles appearing at the duodenum and faeces were fitted to various compartment models to estimate CMRT. Post-abomasal CMRT did not differ among solutes or feed residues of different size and previous digestion and constituted only $5.8 \%$ of the CMRT for the entire gastrointestinal tract. Markers initially applied to orally or ruminally dosed feed residues exhibited profiles in duodenal digesta and faeces conforming to GN $\rightarrow$ G1 flow. Previously undigested, masticated feed residues inserted into the dorsal rumen digesta had longer ruminal CMRT in the GN pool but not the G1 pool than did similarly inserted faecal small particles or normally ingested hay. These results support model assumptions of GN $\rightarrow$ G1 flow within rumen digesta. The results support mechanisms proposed for the GN pool as the 'lagrumination pool' and the G1 pool as the 'mass action turnover pool'. If further validated, rumen CMRT in cattle could be estimated from marker profiles in more easily obtained faeces to estimate ruminal CMRT required for feed evaluation systems.
\end{abstract}

Compartmental models: Digesta flow: Forage particle size

The compartmental mean residence time (CMRT) of feed residues in the digesta of the reticulo-rumen (rumen) is determined by various forces that constrain and propel ruminal escape of undigested feed residues. A major force constraining escape is the competition among ingested feed residues with resident residues of previous meals as the result of the continual mixing of ruminal digesta. If this competition for escape is passive for all feed residues, regardless of their attributes or age in the pool, then CMRT is a function of the mass of resident feed residues and the continued intake rate of feed residues, i.e. mass action dilution turnover rate of the continued intake. Matis (1972) observed that newly ingested feed residues require ageing before acquiring properties required for escape, properties such as particle size reduction for example.
Matis (1972) proposed an age-dependent distribution of residence times to model this initial process constraining escape in contrast to an age-independent, mass action turnover. The age-dependent turnover of undigested feed residues in ruminal digesta could be modelled as a single agedependent mixing pool or a sequence of age-dependent $\rightarrow$ age-independent mixing pools. Ellis et al. (1991, 1994) proposed the 'un-mixing' forces of buoyancy associated with freshly ingested feed residues (Sutherland, 1986) as an age-dependent mechanism. The innate buoyancy of large fragments of vascular tissues provides the initial buoyancy constraining these and entrapped tissue to the dorsal rumen. Subsequent colonization by bacteria then provides a fermentation-based buoyancy that sustains these 'younger' and larger feed residues into digesta flowpaths leading to their

\footnotetext{
Abbreviations: CMRT, compartmental mean residence time; CMRTS, compartmental mean residence time for the system of two compartments; CoDTPA, CrDTPA, cobalt and chromium diethyltriaminepentaacetic acid respectively.

* Approved for publication as TA 23227 by the Director of the Texas Agricultural Experiment Station.

$\dagger$ Corresponding author: Dr W. C. Ellis, fax +1 409845 5292, email w-ellis@tamu.edu
} 
rumination. Rumination of these 'younger' fragments results in reduction in size and complexity of gas-trapping structures together with depletion of readily fermentable substrates. These smaller, aged fragments lose buoyancy in an age-dependent manner and increasingly escape (GN), to the mass action turnover pool from which escape is via simple mass action dilution (G1). Hence the GN $\rightarrow$ G1 flow.

The present experiment was conducted to measure CMRT in gastric and post-gastric segments of digesta due to mixing flow, and the time delay associated with nonmixing displacement flow of feed residues of various sizes and 'ages'. The experimental approach involved use of different rare-earth markers, initially applied to test forage residues, and of solutes that were consumed or injected into different gastric and post-gastric segments of digesta. Test residues and solutes were selected to test various inferences of the sequential lag-rumination, mass action turnover flow model for flux of residues in the rumen digesta (Ellis et al. 1991, 1994).

\section{Materials and methods}

Three Holstein heifers (average body weight $475 \mathrm{~kg}$ ) were given the coastal variety of Bermuda grass (Cynodon dactylon (L.) Pers.) hay (98g crude protein and $503 \mathrm{~g}$ apparent digestible DM per $\mathrm{kg} \mathrm{DM}$ ) ad libitum for 2 weeks before and during the experiment. The heifers were loosehoused in concrete-floored pens and individually tied in these pens during collection of digesta samples. To encourage maximum ad libitum intake, uneaten hay was removed twice daily (at 08.45 and 20.00 hours) and replaced with fresh hay. The heifers consumed approximately $9.5 \mathrm{~kg}$ hay DM daily. The experimental animals had been hand reared, used in similar experiments earlier and were very docile and accustomed to the feeding, care and digesta collection protocol employed. Plots of feed intake and faecal output during the adaptation and digesta collection periods indicated no significant trends in feed intake or faecal output by individual animals during the entire experiment. Absolute feed intake is not reported because interpretation of the results is primarily for material withinanimal and would not be affected by the small fluctuations in voluntary intake.

The heifers had been fistulated and fitted with rumen, abomasal and duodenal cannulas 1 year before the experiment. The rumen cannula (125 mm i.d.) had been placed in the dorsal sac of the rumen and brought through the peritoneum and abdominal musculature to exit through a circular skin incision midway between the 13th left rib and the cranial portion of the left tuber coxa and 400-600 mm below the left transverse processes of the lumbar vertebrae. The abomasal cannula was of moulded silicone, had a $10 \mathrm{~mm}$ i.d. and was placed in the greater curvature of the abomasum approximately $500 \mathrm{~mm}$ caudal to the omasalabomasal junction. It was brought through the intercostal muscles and peritoneum between the right 10th and right 9th ribs and $200-400 \mathrm{~mm}$ dorsal to the chondral portion of the ribs and exteriorized through a circular skin incision in the abdominal wall.

The duodenal cannula $(25.4 \mathrm{~mm}$ i.d.) was moulded of silicone (Ellis et al. 1984b) and positioned in the ascending duodenum on the anti-mesenteric border approximately $50 \mathrm{~mm}$ caudal to the pyloric sphincter. It was exteriorized by blunt circular skin incision and blunt dissections through the intercostal muscles and peritoneum between the right 13 th and right 12th ribs approximately $60-80 \mathrm{~mm}$ ventral to the level of the right transverse processes of the lumbar vertebrae.

\section{Preparation of marked material}

An oesophageally cannulated steer was given access to the experimental hay and the resulting masticate was collected via an open oesophageal fistula and saved for later labelling with a rare-earth marker (masticated hay particles). Faeces from the heifers fed on the hay were collected and wetsieved through a 2370, 1000, 707, 500, 303, 125 and $20 \mu \mathrm{m}$ sieve series. Particles from the faeces which passed the $125 \mu \mathrm{m}$ sieve and were retained by the $20 \mu \mathrm{m}$ sieve (125/20, faecal small particles) and masticated hay particles passing through the $1000 \mu \mathrm{m}$ sieve and retained on the $707 \mu \mathrm{m}$ sieve (1000/707, masticated large hay particles) were collected for subsequent labelling with rare-earth markers.

A portion of the hay on offer was labelled with Sm. La was applied to the array of masticated forage particles. Eu was applied to the 1000/707 masticated large hay particles. The $125 / 20$ particles derived from the faeces were divided into two parts, $\mathrm{Tb}$ was applied to one part and $\mathrm{Sc}$ to the other part.

All rare-earth markers were applied by soaking each type of material separately in $10 \mathrm{ml} 0.1 \mathrm{M}$-sodium acetate-acetic acid solution ( $\mathrm{pH} 4.5$ ) containing $100 \mathrm{mg}$ of the individual rare-earth element per g DM for a minimum of $12 \mathrm{~h}$. The rare-earth-marked material was then rinsed with acetate buffer ( $\mathrm{pH} 4.5$ ) followed by a water rinse (Ellis \& Beever, 1984) to remove any loosely bound rare earths. The marked materials were then refrigerated until given to the animals, except for the marked hay which was dried in a forced draft oven at $60^{\circ}$.

\section{Experimental treatments}

Table 1 summarizes the rare earths used to mark specific materials and the method and site of administration of all marked materials. In addition to the rare-earth-marked forage particles, two solute markers, $0 \cdot 3 \mathrm{M}$-ytterbium acetate and $0.15 \mathrm{M}$-cobalt diethyltriaminepentaacetic acid (CoDTPA) were continuously infused at $10 \mathrm{ml} / \mathrm{h}$ into the abomasum of each heifer via two separate infusion lines. The infusion was started $15 \mathrm{~h}$ before particle dosing and terminated $40 \mathrm{~h}$ after particle dosing. At 07.00 hours, $500 \mathrm{~g}$ Sm-marked hay DM was consumed by each heifer and $50 \mathrm{~g}$ rare-earth-marked masticated hay particles was placed into a cavity excavated in the digesta raft in the dorsal rumen of each heifer near the inner orifice of the cannula. At 07.45 hours, $10 \mathrm{~g}$ DM Tb-marked faecal small particles was similarly inserted into the rumen digesta. Starting at 08.00 hours for the first heifer, 08.10 hours for the second heifer and 08.20 hours for the third heifer, $4 \mathrm{~g}$ DM Sc-labelled faecal small particles, $8 \mathrm{~g}$ DM Eu-labelled masticated hay large particles and $40 \mathrm{ml}$ of $0.3 \mathrm{M}$-chromium DTPA (CrDTPA) were pulse dosed as a slurry into the abomasum through the abomasal cannula. 
Table 1. A summary of the markers used in the present study, the materials or compounds marked and the dosing method and site of marked material dosing

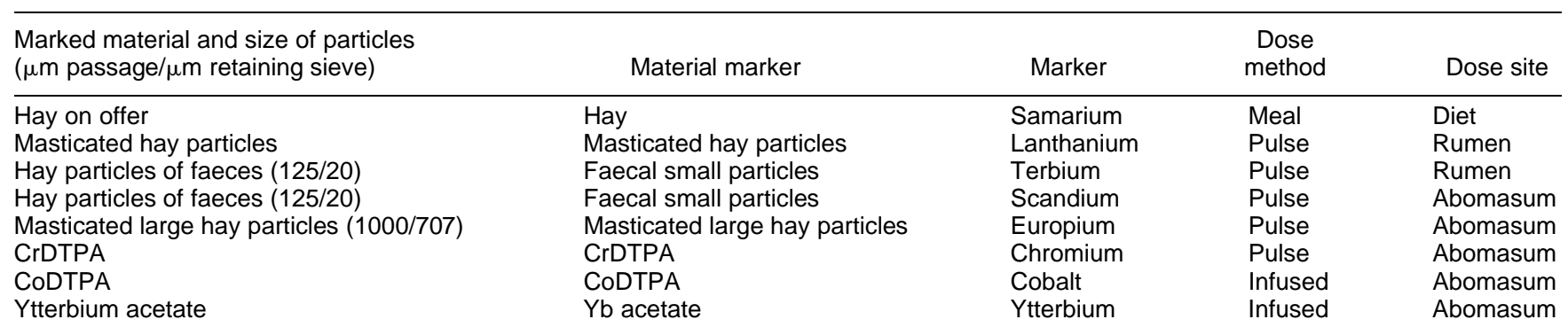

DTPA, diethyltriaminepentaacetic acid.

\section{Sample collection}

Samples (100-200 ml) of duodenal digesta were obtained as individual gushes of digesta from the duodenal cannula subsequent to the initial gush which was discarded. Duodenal samples were collected from each heifer into $236 \mathrm{ml}$ sample cups at $0,0.5,1,1.5,2,2.5,3,3.5$ and $4 \mathrm{~h}$ after the marker materials were dosed into the abomasum. After offering fresh hay (20.00 hours), duodenal samples were taken at hourly intervals until $12 \mathrm{~h}$ after dosing. Thereafter, duodenal samples were collected every $0.5 \mathrm{~h}$ for $3 \mathrm{~h}$, every $1 \mathrm{~h}$ for an additional $8 \mathrm{~h}$ and then every $3 \mathrm{~h}$ for a further $12 \mathrm{~h}$. Sampling was staggered by individual animal according to the $10 \mathrm{~min}$ spacing of the initial dosing of the individual heifers. Faecal samples were collected via induced defaecation at $6 \mathrm{~h}$ intervals during the $72 \mathrm{~h}$ period after the markers were given. Both duodenal and faecal samples were frozen immediately on collection and remained frozen until thawed for analysis.

Duodenal and faecal samples were dried in a forced-draft oven $\left(60^{\circ}\right)$ and then ground through a Wiley mill fitted with a $2 \mathrm{~mm}$ screen. The concentrations of rare-earth markers in the samples were determined by neutron activation analysis (Pond et al. 1985).

\section{Digesta flow models}

The non-linear regression procedure of the Statistical Analysis System (1990; Statistical Analysis Systems Institute Inc., Cary, NC, USA) was used to fit various compartment flow models by least squares to describe the profiles of concentration of the various rare-earth markers in the digesta or faeces. To avoid problems of local solutions, a grid search was employed using an array of initial values for each variable. The array was $0 \cdot 01,0 \cdot 1,1,2,4$ and 8 times a mean value for each variable based on past experience.

The model used, modelling assumptions and the fitting procedures used are described in detail elsewhere (Pond et al. 1988; Ellis et al. 1994). The models used here differed in the number of mixing compartments assumed and the incorporation of various orders of age-dependency in one mixing compartment. As illustrated in detail elsewhere (Ellis et al. 1994), order of age dependency was modelled as varied discrete $(\mathrm{N})$ gamma functions $(\mathrm{G} ; \mathrm{GN})$. A mixing compartment in which all particles were assumed to have an age-independent probability for escape was represented by an exponential distribution of lifetimes or gamma 1 (G1). A mixing compartment in which particles were assumed to have an age-dependent distribution of residence times was modelled by increasing orders of gamma functions, G2, G3 ... GN. An age-independent turnover rate is signified as $k$ with dimensions of $/ \mathrm{h}$. In contrast, the age-dependent turnover rate parameter was signified by $\lambda$ for one compartment and $\lambda_{1}$ for the initial entry compartment of two-compartment models. Non-mixing displacement flow between dose and sampling sites was assumed to be the time delay, signified as $\tau$, between time of marker dose model and estimates of its first detection at the sampling site.

One-compartment, age-independent models are signified as $\mathrm{G} 1 \rightarrow \tau \rightarrow \mathrm{O}$ where $\mathrm{O}$ represents output at the sampling site. One compartment models with increasing order of agedependency are signified as $\mathrm{GN} \rightarrow \tau \rightarrow \mathrm{O}$ where $\mathrm{N} \geqslant 2$ represents the order of gamma function assumed. Twocompartment models with age-independent mixing are similarly signified as $\mathrm{G} 1 \rightarrow \mathrm{G} 1 \rightarrow \tau \rightarrow \mathrm{O}$. Two-compartment models with age-dependent mixing assume that the agedependent mixing compartment is the initial recipient of input and is the faster turnover compartment and they are therefore signified as $\mathrm{GN} \rightarrow \mathrm{G} 1 \rightarrow \tau \rightarrow \mathrm{O}$ where $\mathrm{N} \geqslant 2$.

Each of these models estimated (1) the initial concentration $(\mathrm{C} 0)$ of the marker had it been introduced into and instantaneously mixed with the slower turnover compartment, (2) an age-dependent outflow rate parameter $\left(\lambda\right.$ or $\left.\lambda_{1}\right)$ for the faster-turnover compartment, (3) an age-dependent outflow-rate $\left(k_{2}\right)$ for the slower-turnover compartment, and (4) a time delay $(\tau)$ for first appearance of the rare-earth marker at the sampling site. The CMRT for the ageindependent mixing compartments equals $1 / k_{2}$ and for age-dependent mixing compartments equals $N / \lambda$ or $N / \lambda_{1}$. Thus, the CMRT for the system of two compartments, CMRTS, estimated by the $\mathrm{G} 3 \rightarrow \mathrm{G} 1 \rightarrow \tau \rightarrow \mathrm{O}$, for example, equals $3 / \lambda_{1}+1 / k_{2}$.

Abomasally dosed materials. Various one-compartment models were fitted to marker profiles in the duodenal digesta subsequent to dosing into the abomasum. Models included an age-independent one-compartment model having an exponential distribution of lifetimes with time delay, G1 $\rightarrow$ $\tau \rightarrow \mathrm{O}$, and varied orders of age-dependency, $\mathrm{G} 2 \rightarrow \tau \rightarrow \mathrm{O}$ and $\mathrm{G} 3 \rightarrow \tau \rightarrow \mathrm{O}$.

Continuously infused markers. A G2 $\rightarrow \tau \rightarrow \mathrm{O}$ model was fitted to profiles of marker concentrations in duodenal and faecal digesta subsequent to initiating the continuous infusion of $\mathrm{Yb}$ and $\mathrm{Co}(\mathrm{t})$, and following the cessation of marker infusion. The estimated asymptotic marker concentration $\left(\mathrm{C}_{1}\right)$ achieved via the saturating phase (s) and upon initiating the de-saturating phase (d) and marker 
concentrations $\left(\mathrm{Y}_{\mathrm{s}}\right.$ and $\left.\mathrm{Y}_{\mathrm{d}}\right)$ during saturating and desaturating phases respectively, were linked together to yield a composite set of parameters (rate parameter, $\lambda$ and time-delay parameter, $\tau$ ). The linked model was fitted to marker profiles of $\mathrm{Yb}$ and $\mathrm{Co}$ in the duodenum and faeces. The saturation model for time interval $\tau_{\mathrm{s}}<\mathrm{t}$ was:

$$
\mathrm{Y}_{\mathrm{s}}=\mathrm{C}_{1} \times\left(1-\left(1+\lambda_{\mathrm{s}}\left(\mathrm{t}-\tau_{\mathrm{s}}\right)\right) \times \exp \left(-\lambda_{\mathrm{s}}\left(\mathrm{t}-\tau_{\mathrm{s}}\right)\right)\right)
$$

The desaturation model for time interval $\mathrm{t}>\tau_{\mathrm{d}}$ was:

$$
\mathrm{Y}_{\mathrm{d}}=\mathrm{C}_{1} \times\left(1+\lambda_{\mathrm{d}}\left(\mathrm{t}-\tau_{\mathrm{d}}\right)\right) \times \exp \left(-\lambda_{\mathrm{d}}\left(\mathrm{t}-\tau_{\mathrm{d}}\right)\right)
$$

In the saturating model, $\mathrm{C}_{1}$ is an estimate of the saturated equilibrium concentration of the marker, $\lambda_{s}$ is the age-dependent rate parameter for achieving $\mathrm{C}_{1}, \mathrm{t}$ is time, $\tau_{\mathrm{s}}$ represents the time delay between initiation of marker infusion and first detection of the marker in the duodenal or faecal samples. In the desaturation model, the parameters $\lambda_{\mathrm{d}}$ and $\tau_{\mathrm{d}}$ represent the decay from $\mathrm{C}_{1}$ and time delay after cessation of the marker infusion respectively. The CMRT within this G2 age-dependent mixing compartment was calculated as $2 / \lambda_{1}$.

\section{Statistical analysis}

The general linear models procedure of Statistical Analysis
Systems (1990) was used to test for statistical significance of various response variables (rate parameters, time delay, and CMRT). The basic model utilized was a repeated measures model of Winer (1971): among animals (d.f. 2) and within animals. The latter source of variation was further partitioned into materials (d.f. 2), sample site (d.f. 1) materials by sample site interaction (d.f. 2) and error for pulsed dosed materials. This model does not permit a valid test of significance for animals, for which there was no prime interest. Throughout testing, the residuals of the fitted models showed no evidence of non-normality and no evidence of strong heteroscedasticity for all response variables (i.e. $P>0 \cdot 05$ ). Similar analyses were performed within sample site when significant differences $(P<0.05)$ between sample sites were detected. The Student-Newman-Keuls test was used to test for significance $(P<0.05)$ of sources of variation within those main effects found to be significant.

\section{Results}

\section{Fed and ruminally dosed material}

Profiles of marker concentrations in the duodenal digesta and in the faeces following ingestion of marked hay or
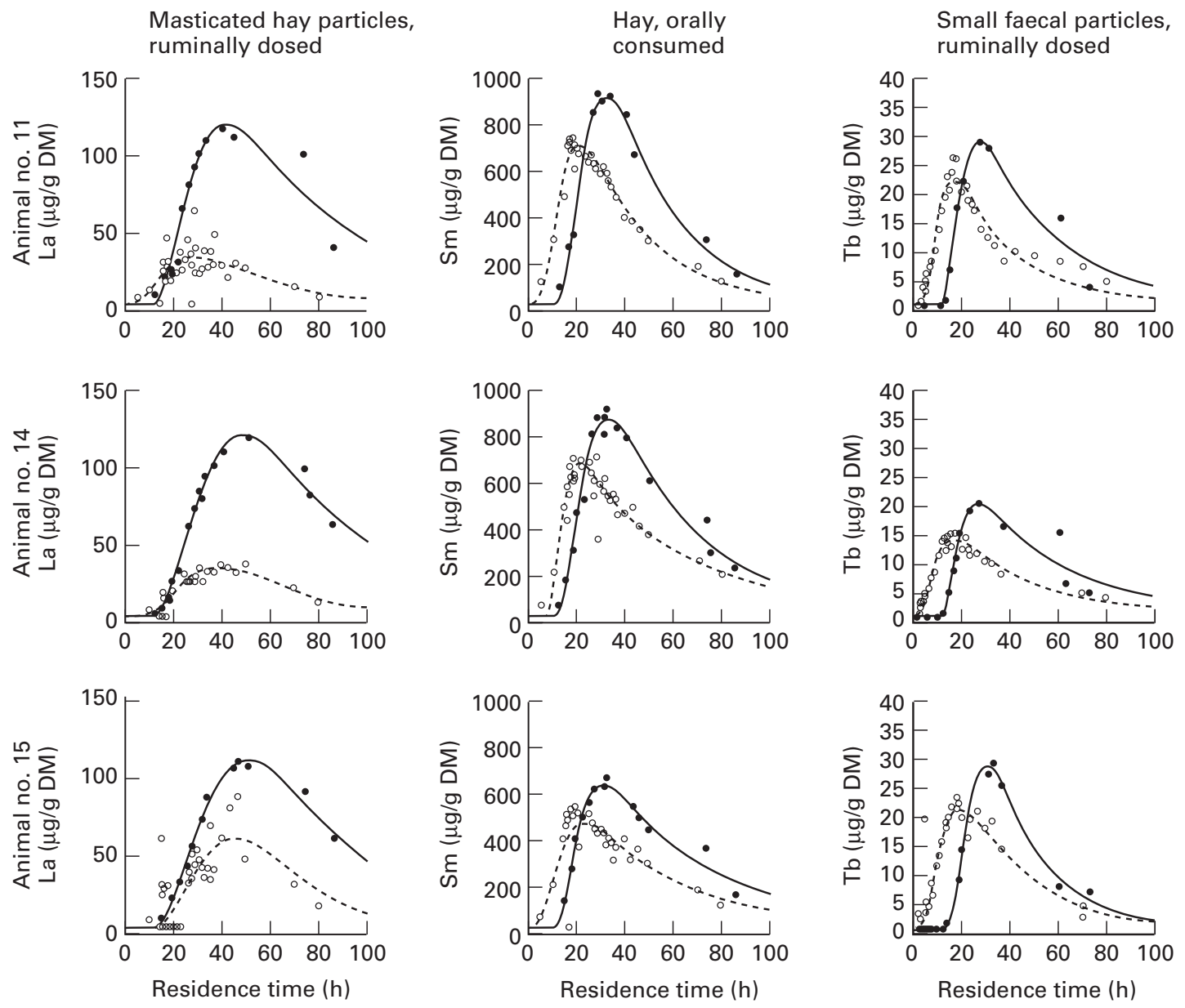

Fig. 1. Profiles of the concentrations of rare-earth markers (lanthanium, samarium and terbium) at the ascending duodenum $(O)$ and in faeces $(\bullet)$ of cattle, and of expected concentrations in the duodenum (--) and faeces $(-)$ subsequent to various materials being inserted into the dorsal rumen digesta or consumed with a meal. Expected concentrations are based on a G3 $\rightarrow \mathrm{G} 1 \rightarrow \tau \rightarrow \mathrm{O}$ model (see pp. 297-298). Profiles are shown for three individual animals. 
Table 2. Rate parameters for the passage of feed particles through the digestive tract of cattle estimated from fitting a G3 $\rightarrow$ $\mathrm{G} 1 \rightarrow \tau \rightarrow \mathrm{O}$ model to the pattern of marker emergence at the duodenum or faeces subsequent to consumption of a meal of samarium-labelled hay or a pulse dose of masticated hay or faecal small particles into the ruminal dorsal strata (Mean values for three cows with their pooled standard errors)

\begin{tabular}{|c|c|c|c|c|c|c|}
\hline \multirow[b]{2}{*}{ Material } & \multicolumn{2}{|c|}{$\lambda_{1}{ }^{*}(/ \mathrm{h})$} & \multicolumn{2}{|c|}{$k_{2} \dagger(/ \mathrm{h})$} & \multicolumn{2}{|c|}{$\tau \ddagger(\mathrm{h})$} \\
\hline & Duodenum & Faeces & Duodenum & $\overline{\text { Faeces }}$ & Duodenum & $\overline{\text { Faeces }}$ \\
\hline Hay & $0.313^{b}$ & $0.250^{b}$ & 0.029 & 0.029 & $3.03^{c}$ & $10.28^{d}$ \\
\hline Masticated hay particles & $0.108^{a}$ & $0.135^{\mathrm{a}}$ & 0.030 & 0.023 & $0.54^{c}$ & $9 \cdot 75^{d}$ \\
\hline Faecal small particles & $0.318^{b}$ & $0.335^{\mathrm{b}}$ & 0.037 & 0.035 & $0.45^{\mathrm{c}}$ & $10 \cdot 96^{d}$ \\
\hline SEM§ & 0.042 & 0.031 & 0.002 & 0.003 & 0.68 & 0.29 \\
\hline
\end{tabular}

${ }_{\mathrm{a}, \mathrm{b}}$ Means values within a column not sharing a common superscript letter were significantly different: $P<0.001$.

$\mathrm{c}, \mathrm{d}$ Means values within a row not sharing a common superscript letter were significantly different: $P<0.0001$.

* The age-dependent rate of escape from the initial entry compartment $(\mathrm{G} 3 \rightarrow$ ).

†The age-independent rate of escape from the terminal compartment $(\mathrm{G} 1 \rightarrow)$.

$¥$ The time delay for displacement flow.

$\S$ Standard error of mean parameter estimate within site.

dosing into the dorsal ruminal digesta are plotted in Fig. 1. These profiles are typified by a time-delay phase of undetectable marker concentrations (not clearly discernible for abomasal profiles), a less than vertical ascending phase to a peak concentration followed by a descending phase of marker concentrations. Such profiles typify outflow from two sequential mixing compartments following a passage lag time.

Fitting two-compartment models with increasing order of age dependency ( $\mathrm{G} 1 \rightarrow \mathrm{G} 1 \rightarrow \tau \rightarrow \mathrm{O}$ through G6 $\rightarrow \mathrm{G} 1 \rightarrow \tau$ $\rightarrow \mathrm{O})$ yielded similar error mean squares. Increasing the order of age dependency resulted in improved resolution between the two rate parameters $\left(\lambda_{1}\right.$ and $\left.k_{2}\right)$ and reductions in the standard errors for each parameter, thus mitigating the problem of multicollinearity (Seber \& Wild, 1989). Four of the eighteen data sets required fitting of a G3 $\rightarrow \mathrm{G} 1 \rightarrow \tau \rightarrow \mathrm{O}$ model to resolve the two rate parameters by a factor of 1.6 which in present and past experience (Table 6 of Pond et al. 1988) is sufficient to yield acceptable standard errors for each rate parameter (see also a graphic example of this type of response in Fig. 10 of Ellis et al. 1994). Therefore, the profiles of marker concentration observed at the duodenum and faeces for dietary and ruminally dosed markers and marker concentrations expected by the $\mathrm{G} 3 \rightarrow \mathrm{G} 1 \rightarrow \tau \rightarrow \mathrm{O}$ model are plotted in Fig. 1. Parameters estimated by the G3 $\rightarrow \mathrm{G} 1 \rightarrow \tau \rightarrow \mathrm{O}$ model are summarized in Table 2 .

As expected, the $\tau$ for all materials estimated via sampling duodenal digesta was significantly (i.e. $P<0 \cdot 01$ ) smaller than $\tau$ estimated via sampling faecal excreta. The rate parameters $\lambda_{1}$ and $k_{2}$ did not differ significantly $(P>$ 0.05 ) by sampling site within materials. However, the rate parameter $\lambda_{1}$ estimated at both sampling sites for ruminally dosed masticated hay particles was smaller $(P<0.05)$ than for the other materials. In contrast, values for the rate parameter $k_{2}$ estimated at both sampling sites did not differ $(P>0.05)$ among materials.

\section{Abomasally dosed materials}

The profiles of marker concentrations in the duodenal digesta and the faeces subsequent to pulse dosing into the abomasum are plotted in Fig. 2. Following a time-delay phase (not graphically discernible), the profiles of marker concentrations in both duodenal and faecal samples were typified by a near vertical ascending phase to a peak concentration followed by a descending phase. Visually, this profile suggests that flow beyond the cranial abomasal dosing site conformed to a single mixing compartment. However, fitting an age-dependent, one-compartment or two-compartment model resulted in considerable reductions in mean model error mean squares for duodenal and faecal sampling sites (for faecal small particles) and faecal sampling site (for masticated large hay particles) (Table 3). Also, closer examination of marker profiles via logarithmic scaling (Fig. 3) indicated an even slower, third turnover pool between the anterior abomasum and the ascending duodenum. This third compartment is especially evident for small faecal particles and may be an artifact due to the greater analytical sensitivity for the Sc marker and possibly a physiologically excessive dose of small faecal particles into the anterior abomasum. Moreover, it is apparent from the logarithmic scaling that the exponential decline in marker concentrations in the abomasum and faeces failed to parallel each other as would be expected if no further mixing flow occurred caudal to the duodenum.

These comparisons suggest that digesta flow through the abomasum conformed to expectations of either an agedependent mixing compartment (the $\mathrm{G} 2 \rightarrow \tau \rightarrow \mathrm{O}$ model) or a model containing two mixing compartments. Parameters estimated from fitting a two-compartment model, $\mathrm{G} 3 \rightarrow \mathrm{G} 1 \rightarrow \tau \rightarrow \mathrm{O}$, are summarized in Table 4 .

Significant differences $(P<0.01)$ existed between duodenal and faecal sampling sites for each of the three model parameters estimated for each abomasally dosed material. As suggested by the near vertical ascending phase, the faster turnover rate parameter, $\lambda_{1}$, was relatively large, in the order 20-50/h which, for a G3 order of age dependency would represent a CMRT $\left(3 / \lambda_{1}\right)$ of only 0.06 to $0.15 \mathrm{~h}$. The $k_{2}$ for flow from the cranial abomasum to the ascending duodenum was in the order of $1 \cdot 5 / \mathrm{h}$. The value of $1 \cdot 5 / \mathrm{h}$ represents a CMRT of $0.67 \mathrm{~h}(1 / 1.5)$ and, being approximately 3 -fold that estimated for flow from the ascending duodenum to the faeces, indicates the minor contribution of post-duodenal mixing.

\section{Continuously infused markers}

The profiles of faecal marker concentrations of continuously infused solutes into the abomasum are plotted in Fig. 4. An 

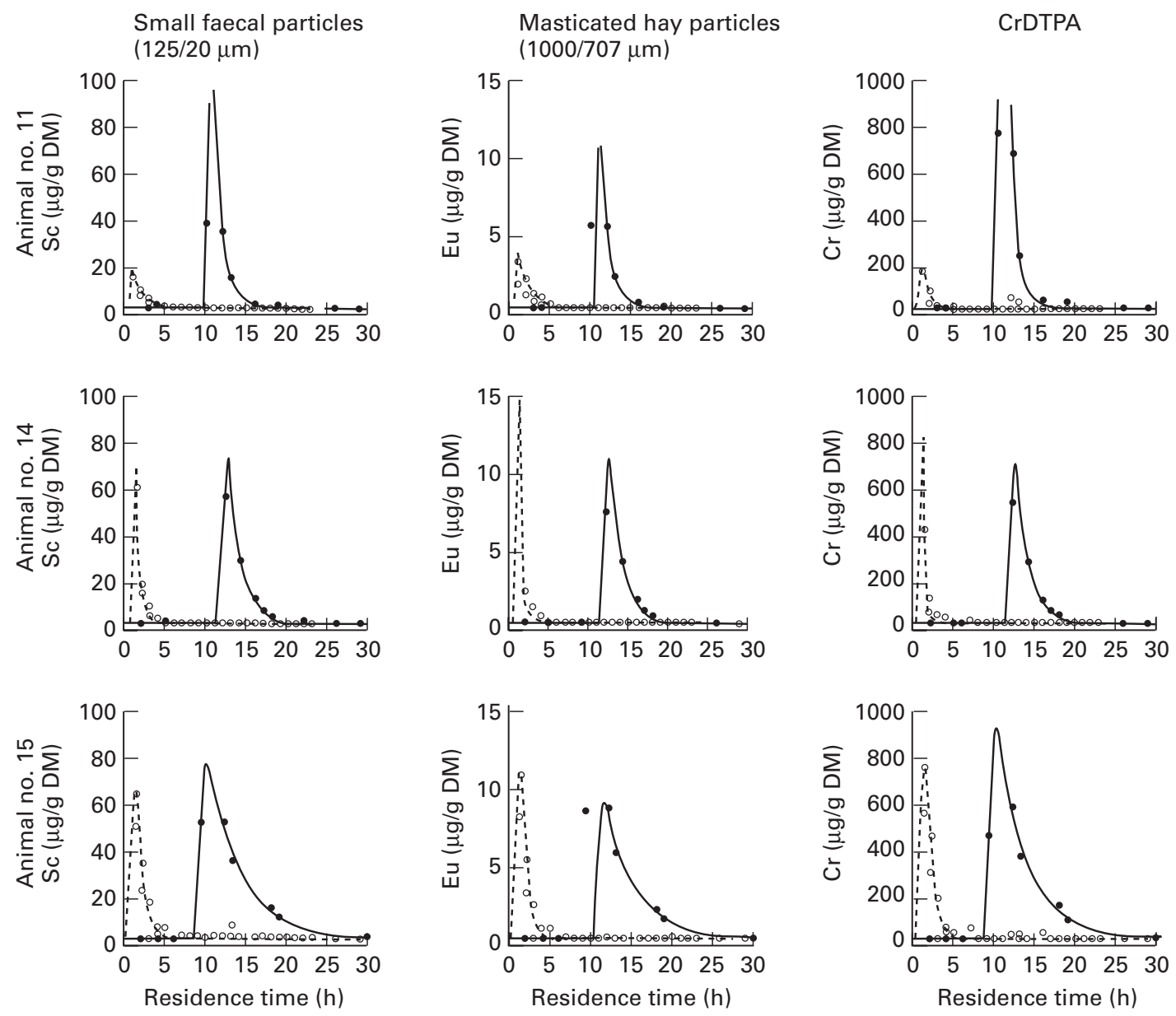

Fig. 2. Profiles of the concentrations of rare-earth markers (scandium, europium) and chromium at the ascending duodenum $(\bigcirc)$ and in faeces $(\bullet)$ of cattle, and of expected concentrations in the duodenum (---) and faeces (-) subsequent to various materials being pulse-dosed into the anterior abomasum. Expected concentrations are based on a G3 $\rightarrow \mathrm{G} 1 \rightarrow \tau \rightarrow \mathrm{O}$ model (see pp. 297-298). Profiles are shown for three individual animals. CrDTPA, chromium diethyltriaminepentaacetic acid.

Table 3. Model error mean square values resulting from fitting various models to marker profile at the duodenum and faeces subsequent to a pulse dose into the abomasum of labelled faecal small particles, hay masticate or chromium diethyltriaminepentaacetic acid (CrDTPA)

(Mean values for three observations)

\begin{tabular}{|c|c|c|c|}
\hline Material & Model & Duodenum & Faeces \\
\hline $\begin{array}{l}\text { Faecal small particles } \\
\text { Faecal small particles } \\
\text { Faecal small particles } \\
\text { Faecal small particles } \\
\text { Faecal small particles }\end{array}$ & $\begin{array}{l}\mathrm{G} 1 \rightarrow \tau \rightarrow \mathrm{O}^{*} \\
\mathrm{G} 2 \rightarrow \tau \rightarrow \mathrm{O}^{*} \\
\mathrm{G} 1 \rightarrow \mathrm{G} 1 \rightarrow \tau \rightarrow \mathrm{O} \dagger \\
\mathrm{G} 2 \rightarrow \mathrm{G} 1 \rightarrow \tau \rightarrow \mathrm{O} \dagger \\
\mathrm{G} 3 \rightarrow \mathrm{G} 1 \rightarrow \tau \rightarrow \mathrm{O} \dagger\end{array}$ & $\begin{array}{r}117 \\
96 \\
88 \\
88 \\
88\end{array}$ & $\begin{array}{r}156 \cdot 0 \\
8.7 \\
4.0 \\
4.0 \\
4.0\end{array}$ \\
\hline $\begin{array}{l}\text { Masticated large hay particles } \\
\text { Masticated large hay particles } \\
\text { Masticated large hay particles } \\
\text { Masticated large hay particles } \\
\text { Masticated large hay particles }\end{array}$ & $\begin{array}{l}\mathrm{G} 1 \rightarrow \tau \rightarrow \mathrm{O}^{*} \\
\mathrm{G} 2 \rightarrow \tau \rightarrow \mathrm{O}^{*} \\
\mathrm{G} 1 \rightarrow \mathrm{G} 1 \rightarrow \tau \rightarrow \mathrm{O} \dagger \\
\mathrm{G} 2 \rightarrow \mathrm{G} 1 \rightarrow \tau \rightarrow \mathrm{O} \dagger \\
\mathrm{G} 3 \rightarrow \mathrm{G} 1 \rightarrow \tau \rightarrow \mathrm{O} \dagger\end{array}$ & $\begin{array}{l}3.2 \\
2.2 \\
1.9 \\
7.7 \\
7.7\end{array}$ & $\begin{array}{l}4 \cdot 8 \\
0 \cdot 1 \\
0.1 \\
0.05 \\
0.04\end{array}$ \\
\hline $\begin{array}{l}\text { CrDTPA } \\
\text { CrDTPA } \\
\text { CrDTPA } \\
\text { CrDTPA } \\
\text { CrDTPA }\end{array}$ & $\begin{array}{l}\mathrm{G} 1 \rightarrow \tau \rightarrow \mathrm{O}^{*} \\
\mathrm{G} 2 \rightarrow \tau \rightarrow \mathrm{O}^{*} \\
\mathrm{G} 1 \rightarrow \mathrm{G} 1 \rightarrow \tau \rightarrow \mathrm{O}+ \\
\mathrm{G} 2 \rightarrow \mathrm{G} 1 \rightarrow \tau \rightarrow \mathrm{O}+ \\
\mathrm{G} 3 \rightarrow \mathrm{G} 1 \rightarrow \tau \rightarrow \mathrm{O}+\end{array}$ & $\begin{array}{r}14438 \\
9734 \\
8886 \\
9342 \\
9969\end{array}$ & $\begin{array}{r}48021 \\
2500 \\
1280 \\
947 \\
843\end{array}$ \\
\hline
\end{tabular}

${ }^{*} \mathrm{G} 1 \rightarrow \tau \rightarrow \mathrm{O}$ is one age-independent compartment mixing flow model with mixing flow segment $(\mathrm{G} 1 \rightarrow)$, displacement flow segment $(\tau \rightarrow)$ and output $(\mathrm{O})$. G2 $\rightarrow \tau \rightarrow \mathrm{O}$ is an age-dependent mixing compartment. $+\mathrm{GN} \rightarrow \mathrm{G} 1 \rightarrow \tau \rightarrow \mathrm{O}$ is a sequential, two-compartment model with age-independent flow (G1 $\rightarrow$ ), in each compartment, or age-dependent $(\mathrm{G} 2 \rightarrow)$ flow or age-dependent $(\mathrm{G} 3 \rightarrow)$ flow through the initial entry compartment and age-independent flow $(\mathrm{G} 1 \rightarrow)$, flow in the terminal compartment followed by a displacement flow segment $(\tau \rightarrow)$, before exiting the gastrointestinal tract $(\mathrm{O})$. 
Small faecal particles $(125 / 20 \mu \mathrm{m})$
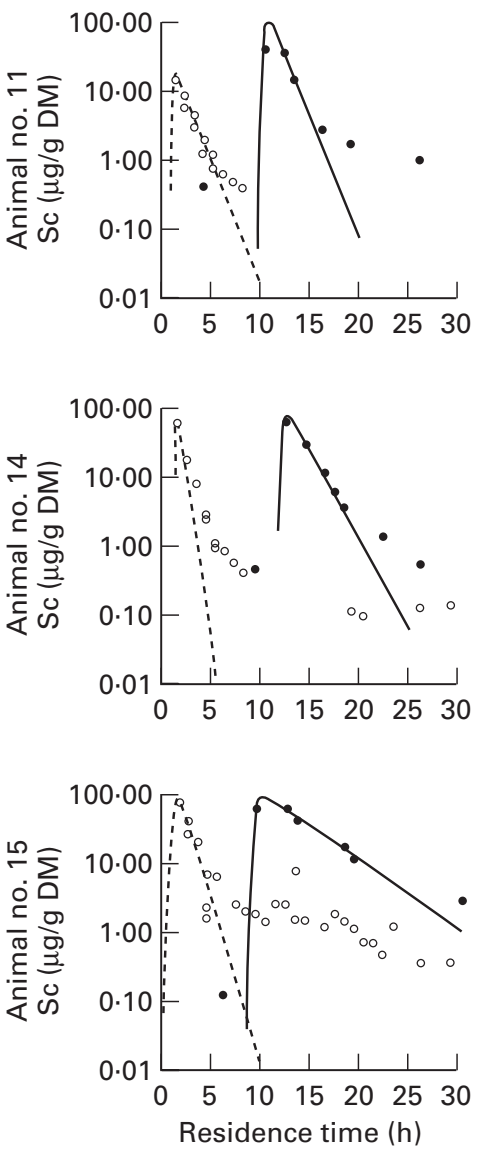

Masticated hay particles $(1000 / 707 \mu \mathrm{m})$
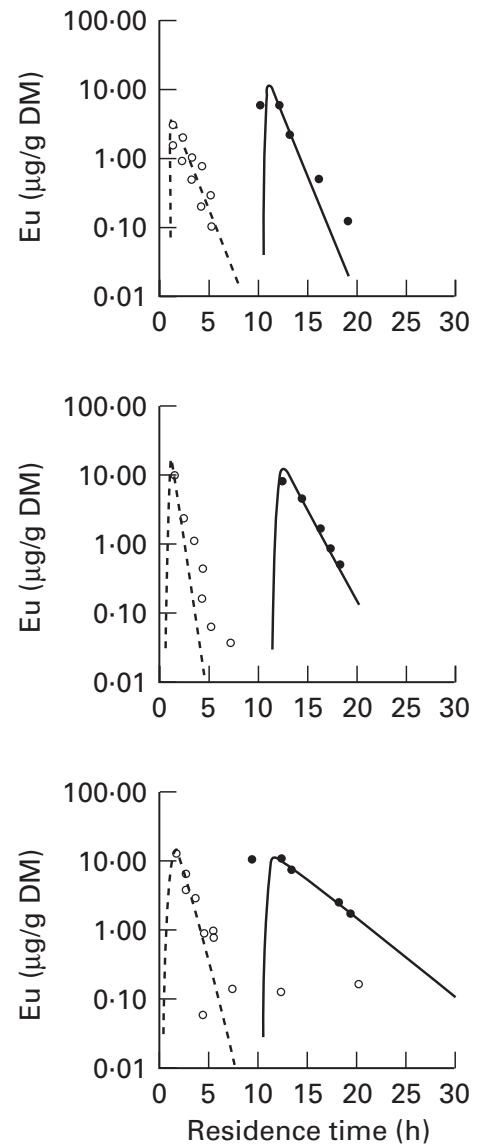

CrDTPA
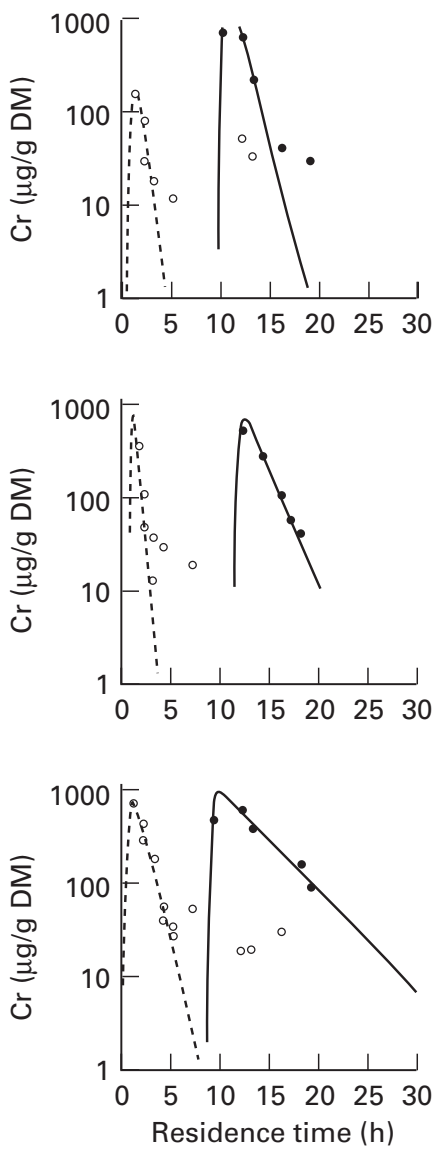

Fig. 3. Logarithmic scaled marker profiles of the concentrations of rare-earth markers (scandium, europium) and chromium at the ascending duodenum $(O)$ and in faeces $(\bullet)$ of cattle, and of expected concentrations in the duodenum (---) and faeces $(-)$ subsequent to various materials being pulse-dosed into the anterior abomasum. Expected concentrations are based on a G3 $\rightarrow \mathrm{G} 1 \rightarrow \tau \rightarrow \mathrm{O}$ model (see pp. 297-298). Profiles are shown for three individual animals. CrDTPA, chromium diethyltriaminepentaacetic acid.

interruption in infusion of CoDTPA into heifer 11 caused the slow ascending phase observed for this animal. However, turnover rates estimated for this animal did not appear to be different from values estimated for the other animals, demonstrating the robustness achieved by linking the saturating and de-saturating phases via this model.
Means by materials for the parameters are summarized in Table 5. The age-dependent turnover rate parameter was significantly larger $(P<0.05)$ and the time delay smaller when estimated from duodenal $v$. faecal sampling, reflecting the occurrence of additional turnover and time-delay pools subsequent to the ascending duodenum.

Table 4. Rate parameters for the passage of feed particles through the digestive tract of cattle estimated from fitting a G3 $\rightarrow$ $\mathrm{G} 1 \rightarrow \tau \rightarrow \mathrm{O}$ model to the pattern of marker emergence at the duodenum and faeces subsequent to a pulse dose into the abomasum of labelled faecal small particles, hay masticate or chromium diethyltriaminepentaacetic acid (CrDTPA)

(Mean values for three cows with their pooled standard errors)

\begin{tabular}{|c|c|c|c|c|c|c|}
\hline \multirow[b]{2}{*}{ Material } & \multicolumn{2}{|c|}{$\lambda_{1}{ }^{*}(/ \mathrm{h})$} & \multicolumn{2}{|c|}{$k_{2} \dagger(/ h)$} & \multicolumn{2}{|c|}{$\tau \ddagger(\mathrm{h})$} \\
\hline & Duodenum & Faecal & Duodenum & Faecal & Duodenum & Faecal \\
\hline Faecal small particles & $53 \cdot 7^{a}$ & $6 \cdot 4^{\mathrm{b}}$ & $1 \cdot 27^{\mathrm{a}}$ & $0.53^{b}$ & $0.53^{a}$ & $9 \cdot 72^{b}$ \\
\hline Masticated large hay particles & $31 \cdot 0^{a}$ & $8.2^{b}$ & $1.38^{a}$ & $0.57^{\mathrm{b}}$ & $0.45^{a}$ & $10 \cdot 67^{\mathrm{b}}$ \\
\hline CrDTPA & $22 \cdot 6^{\mathrm{a}}$ & $6 \cdot 4^{b}$ & $1.85^{\mathrm{a}}$ & $0.60^{\mathrm{b}}$ & $0.30^{\mathrm{a}}$ & $9.78^{\mathrm{b}}$ \\
\hline SEM§ & $8 \cdot 2$ & $3 \cdot 2$ & 0.11 & 0.02 & 0.11 & $1 \cdot 10$ \\
\hline
\end{tabular}

${ }^{a, b}$ Mean values within a row for each sampling site not sharing a common superscript letter were significantly different: $P<0.05$

* The age-dependent rate of escape from the initial entry compartment $(\mathrm{G} 3 \rightarrow)$.

† The age-independent rate of escape from the terminal compartment $(\mathrm{G} 1 \rightarrow)$.

$¥$ The time delay for displacement flow.

$\S$ Standard error of mean parameter estimate within site. 

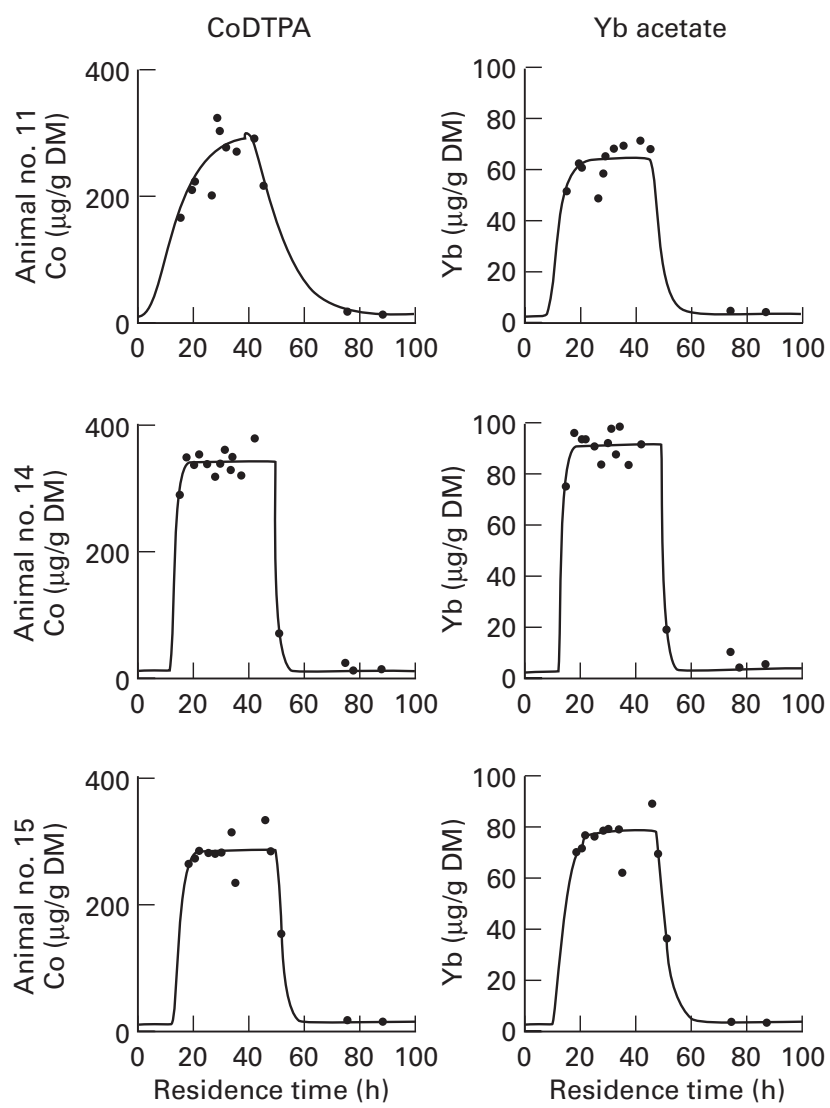

Fig. 4. Profiles of the concentrations of markers (cobalt and ytterbium) at the ascending duodenum $(O)$ and in faeces $(\bullet)$ of cattle, and of expected concentrations in the duodenum (---) and faeces (-) subsequent to various materials being pulse-dosed into the anterior abomasum. Expected concentrations are based on a linked saturation-desaturation $\mathrm{G} 2 \rightarrow \tau \rightarrow \mathrm{O}$ model (see p. 298). Profiles are shown for three individual animals. CoDTPA, cobalt diethyltriaminepentaacetic acid.

\section{Discussion}

\section{Compartmental models and age-dependency}

Compartmental models express the dilution rate that feed residues undergo due to continued mixing of intake with

Table 5. Rate parameters for the passage of feed particles through the digestive tract of cattle estimated from fitting a $\mathrm{G} 2 \rightarrow \tau \rightarrow \mathrm{O}$ model to the pattern of marker emergence at the faeces subsequent to initiation and termination of a continuous infusion of marked materials into the abomasum

(Mean values for three observations)

\begin{tabular}{lccr}
\hline Material infused & Sampling site & $\lambda^{\star}(\mathrm{h})$ & $\tau \dagger(\mathrm{h})$ \\
\hline CoDTPA & Duodenum & $1.26^{\mathrm{a}}$ & $1.66^{\mathrm{a}}$ \\
Yb Acetate & Duodenum & $1.27^{\mathrm{a}}$ & $1.87^{\mathrm{a}}$ \\
CoDTPA & Faeces & $0.94^{\mathrm{b}}$ & $11.45^{\mathrm{b}}$ \\
Yb Acetate & Faeces & $0.66^{\mathrm{b}}$ & $9.19^{\mathrm{b}}$
\end{tabular}

CoDTPA, cobalt diethyltriaminepentaacetic acid.

a,b Mean values within a column with different superscript letters were significantly different: $P<0.05$

* The age-dependent rate of escape from a single mixing compartment $(\mathrm{G} 2 \rightarrow$ ). $\dagger$ The time delay for displacement flow. undigested feed residues resident in the rumen from a succession of previous intakes. The validity of rare-earth markers as flow markers for indigestible residues has been demonstrated (Wylie et al. 1986; Faichney et al. 1989; Ellis et al. 1994). Matis (1972) noted that the digestion processes in the rumen mimic an age-dependent process in that ageing (or time) is required for ingested residues to progressively acquire attributes essential for their escape (e.g. particle size reduction). Matis (1972) chose various discrete gammadistributed lifetimes, $\mathrm{G}$ of $\mathrm{N} \geqslant 2$, to model such nonexponential, age-dependent turnover. France et al. (1985), proposed the term 'distributed lags' to characterize the agedependent, entry mixing compartment described by Matis (1972). Mathematically, the distributed lag model proposed by France et al. (1985) is identical in concept and implementation to that proposed by Matis (1972).

\section{Estimation of model parameters}

The spectrum of age-dependent processes affecting ruminal flow can be described as a single age-dependent compartment (Matis, 1972; Ellis et al. 1994). However, two-compartment, age-dependent (G1), age-independent models (GN where $\mathrm{N}$ is an integer greater than 2 ), $\mathrm{GN} \rightarrow \mathrm{G} 1 \rightarrow \mathrm{O}$ fitted to ruminal outflow are preferred in order to separately delineate residence time distributions in the initial entry, GN, non-escapable compartment from age-independent, mass action dilution and terminal rumen escape compartment, G1.

Two-compartment models specifying different residence time distributions for each compartment allow resolution of otherwise irresolvable rate parameters. For example, fitting $\mathrm{G} 1 \rightarrow \mathrm{G} 1 \rightarrow \tau \rightarrow \mathrm{O}$ to profiles of marker concentration in duodenal digesta yielded excellent fit for all data sets. However, estimates of rate parameters $\lambda_{1}$ and $k_{2}$ were essentially equal $\left(\lambda_{1} / k_{2} \cong 0.99\right)$ for the majority of the data sets. Essential equality of parameters indicates either (1) equal compartmental size and therefore equal ageindependent, exponential escape rates and consequent large errors of estimation, or (2) that flow was via a nonexponential, age-dependent process (Pond et al. 1988). Specifying different orders of age dependency in the faster turnover compartment provides models with greater contrasts in residence time distribution between each compartment and thereby allows mathematical resolution of the two compartments with acceptable errors (less than $5 \%$ ) with the rate parameter(s). Illustrations of single-compartment models with orders of $\mathrm{N}$ larger than that given here are given by Matis et al. (1989). Four of the eighteen data sets required fitting of the $\mathrm{G} 3 \rightarrow \mathrm{G} 1 \rightarrow \tau \rightarrow \mathrm{O}$ model to minimize the asymptotic standard error approximation for the estimated rate parameters for all except one material in duodenal digesta.

The importance of an adequate number and distribution of samples in the estimation of all parameters cannot be over-emphasized (see Fig. 10 and related discussion on page 722 of Ellis et al. 1994). A sufficient number of, and strategically spaced, samples are especially critical in resolving the discrete time delay, $\tau$, from an age-dependent distribution of turnover rates, $\lambda_{1}$ (see Fig. 6 of Pond et al. 1988). The criterion of adequate data is the presence of 
Table 6. Summary of compartmental mean residence times (CMRT; $h$ ) for the age-dependent compartment (CMRT1), for the age-independent compartment (CMRT2), and for the two mixing compartments (CMRTS), and time delays (h) estimated for various materials and various sampling sites

\begin{tabular}{|c|c|c|c|c|c|c|c|c|c|}
\hline \multirow[b]{2}{*}{ Dose site } & \multirow[b]{2}{*}{ Material dosed } & \multicolumn{4}{|c|}{ Duodenal sampling site } & \multicolumn{4}{|c|}{ Faecal sampling site } \\
\hline & & CMRT1* & CMRT2† & CMRTS $\ddagger$ & $\overline{\tau \S}$ & CMRT1* & CMRT2† & CMRTS $\ddagger$ & $\tau \S$ \\
\hline$\overline{\text { Diet }}$ & Hay & $10 \cdot 4^{a}$ & $36 \cdot 1$ & $46 \cdot 6$ & 3.0 & $12 \cdot 0^{\mathrm{a}}$ & $35 \cdot 2$ & $47 \cdot 3$ & $10 \cdot 3$ \\
\hline Rumen & Masticated hay particles & $29 \cdot 4^{\mathrm{b}}$ & 33.8 & 63.8 & 0.5 & $22 \cdot 2^{\mathrm{b}}$ & 44.7 & 67.5 & 9.8 \\
\hline Rumen & Faecal small particles & $9 \cdot 8^{a}$ & $27 \cdot 4$ & $37 \cdot 2$ & 0.5 & $9 \cdot 1^{a}$ & $30 \cdot 0$ & 39.1 & 11.0 \\
\hline Abomasum & Faecal small particles & 0.24 & 0.90 & 1.14 & 0.53 & 0.47 & 2.48 & 2.96 & 9.7 \\
\hline Abomasum & Masticated large hay particles & 0.25 & 0.82 & 1.08 & 0.45 & 0.41 & $2 \cdot 24$ & 2.65 & $10 \cdot 7$ \\
\hline Abomasum & CrDTPA & 0.42 & 0.62 & 1.04 & 0.30 & 0.47 & 2.23 & 2.74 & 9.8 \\
\hline Abomasum & CoDTPA & NE & NE & 1.08 & 0.66 & NE & NE & 2.88 & 8.4 \\
\hline Abomasum & $\mathrm{Yb}$ Acetate & NE & NE & 1.18 & 0.54 & NE & NE & 1.49 & 9.2 \\
\hline Mean, abomasum dose site & & 0.31 & 0.78 & 1.10 & 0.42 & 0.45 & $2 \cdot 32$ & 2.77 & $10 \cdot 1$ \\
\hline SEMI & & 0.20 & 0.81 & 0.88 & 0.38 & 0.39 & 0.97 & 1.08 & 1.1 \\
\hline
\end{tabular}

NE, not estimated; CrDTPA, CoDTPA, chromium and cobalt diethyltriaminepentaacetic acids respectively.

${ }^{a, b}$ Mean values within a column with different superscript letters were significantly different: $P<0.05$.

${ }^{*}$ CMRT $1=3 / \lambda$ or $3 / \lambda_{1}$.

$+\mathrm{CMRT2}=2 / k_{2}$.

$\ddagger$ CMRTS $=$ CMRT $1+$ CMRT2.

$\S$ Time delay.

I Standard error (from ANOVA) of mean parameter estimate within site.

observed values in the vicinity of the parameter being estimated. For example, in the current data, the resolution of a discrete time delay of $0.5 \mathrm{~h}$ in duodenal digesta (Table 2) from age-dependent distributed flow (Fig. 1) was possible only because $0,0.5$ and $1.0 \mathrm{~h}$ values were available for duodenal digesta. In functional terms, this time delay can be presumed to precede the age-dependent compartment and could be more representatively symbolized as $\tau \rightarrow \mathrm{G} 3 \rightarrow \mathrm{G} 1 \rightarrow \mathrm{O}$.

\section{Compartmental Mean Residence Time}

Because the rate parameters $\lambda_{1}$ and $k_{2}$ describe different attributes of residence distributions, they cannot be compared as such. The associated CMRT can be compared with each other and with $\tau$. CMRT for each pool can be estimated as CMRT $1=\mathrm{N} / \lambda_{1}$ and CMRT2 $=1 / k_{2}$ (Ellis et al. 1994). These parameters for the current study are summarized together with $\tau$ in Table 6.

The masticated hay particles inserted into the rumen digesta were obtained as an oesophageal masticate of the same hay as was ingested by these experimental animals. Thus, masticated hay particles inserted into ruminal digesta should have been representative of those derived via normal ingestion. However, the CMRT1 for masticated hay particles inserted into ruminal digesta were significantly longer than the CMRT1 for normally ingested hay or for faecal small particles similarly inserted into the ruminal digesta. These results suggest that small samples $(4-10 \mathrm{~g})$ inserted into ruminal digesta, and especially of large hay particles, may be positioned outside the normal flow paths that the age-dependent flow processes normally encounter by the array of ingested hay.

It is logical to conceive that some sites within ruminal digesta may be poorly mixed and flow of small samples placed in these poorly mixed and 'flow stagnant' sites may be unrepresentative (Vega \& Poppi, 1997) of the flowpaths of a larger population of normally ingested feed residues. Pond et al. (1989) noted that turnover of feed residues inserted into the dorsal digesta, and especially $\lambda_{1}$, decreased with duration of a meal. They proposed flow paths in which the caudo-dorsal ruminal digesta may be a 'flow stagnant' site for some hours after a meal. Thus, $\lambda_{1}$ and $k_{2}$ should be estimated from marker profiles derived from the total of a normally ingested meal.

The importance of particle size and fermentation-based buoyancy of particles is indicated by comparisons between masticated hay particles and small faecal particles when each were placed into the same site within ruminal digesta. The CMRT1 was longer $(P=0.05)$ for masticated hay particles $v$. small faecal particles when sampled at both the duodenum $(29.4 v .9 .8 \mathrm{~h})$ and the faeces $(22.2 v .9 .1 \mathrm{~h}$, Table 6). In contrast, although numerically longer, the CMRT2 for these same particles did not differ statistically $(P>0.05)$ at either sampling site. Thus, the combined effects of buoyancy and particle size per se had their greatest impact in the age-dependent compartment of ruminal digesta (Table 6). The CMRTS for small faecal particles observed here for faecal sampling was 0.58 that for masticated hay particles. This is comparable to the CMRTS observed by Luginbuhl et al. (1994) for total faecal particles $v$. masticated hay of 0.74 using similar hay and marking and insertion techniques as used in the current study.

These responses are consistent with the suggestion that the age-dependent compartment is a functional representation of the more buoyant, large-particle-based rumination pool while the age-independent compartment is a function of the mass action dilution turnover of smaller fermentatively spent particles escaping the rumen (Ellis et al. 1991, 1994, 1999). The mass action, mixing, diluting compartment was the largest compartment, its CMRT2 representing a mean of 0.75 of the CMRTS $(\mathrm{CMRTS}=\mathrm{CMRT} 1+\mathrm{CMRT} 2)$ for normally ingested hay and faecal small particles whether estimated in duodenal digesta or the faeces.

The CMRT1, CMRT2 and/or CMRTS did not differ among marked feed residues and solutes inserted into the abomasum and sampled at either the ascending duodenum or faeces (Table 6). This lack of difference among these 
materials contrasts with differential flow of these same materials through ruminal digesta and is consistent with the lack of selective constraints on flow of these materials through post-gastric segments of digesta. Values for the discrete time delay, $\tau$, for flow from the mid-abomasum to the ascending duodenum did not differ statistically $(P>$ 0.05 ) among materials and averaged $0.42 \mathrm{~h}$ for flow to the ascending duodenum and $9.2 \mathrm{~h}$ for flow to the faeces (Table 6). The mean $\tau$ for abomasal to duodenal displacement flow was $0.42 \mathrm{~h}$, a value not significantly different $(P>0.05)$ for flow of feed residues inserted into the ruminal digesta $(0.5 \mathrm{~h})$ or normally consumed $(3 \mathrm{~h})$. The problem of distinguishing a statistically significant $\tau$ from $\lambda_{1}$ has been discussed. Thus, if a discrete passage time delay time in the ruminal-omasal digesta exists, it appears to be in the order of $2.5 \mathrm{~h}(3.0-0.5=2.5 \mathrm{~h})$.

\section{Terminology}

Terminology for describing kinetics of digesta transfer has been inconsistent. To avoid confusion in interpretation, it is proposed that a discrete lag time, $\tau$, for an entity retaining its chemical identity (i.e. digestion lag, $\tau_{\mathrm{h}}$ ) or physical location (i.e. passage lag, $\tau_{\mathrm{p}}$ ) should be used. The use of the term 'discrete' as an adjective is necessary to differentiate a discrete time that particles are unable to escape from the rumen digesta as opposed to the term of 'distributed lags' proposed by France et al. (1985) for age-dependent turnover. For delays in time associated with non-mixing flow between two different physical locations, the term transit time, $\delta$, appears most appropriate. Thus, abbreviation to indicate for flow sequence in compartmental models applied to the ruminant gastrointestinal tract based on the current results would be, for example: $\rightarrow \tau_{\mathrm{p}} \rightarrow \mathrm{GN} \rightarrow \mathrm{G} 1 \rightarrow \delta \rightarrow \mathrm{O}$.

Because of relatively slow mixing of rumen digesta, major problems exist in both conceptually and analytically differentiating discrete $\tau_{\mathrm{p}}$ from 'distributed $\tau_{\mathrm{p}}$ ' as conceptualized by France et al. (1985). Therefore, for other than conceptual applications, it seems appropriate to use models without $\tau_{\mathrm{p}}$ and, consequently, merge $\tau_{\mathrm{p}}$ with GN.

Ellis et al. $(1994,1999)$ proposed that the age-dependent turnover compartment should be termed the "lag-rumination' pool because it represents the initial entry pool as indicated by its age-dependent distribution of residence times. As demonstrated here, this lag-rumination pool is the principal source of rumen-inescapable particles and particles that are subjected to rumination and fermentation before becoming less buoyant and escaping to the second pool. The second sequential rumen mixing pool, proposed to be termed the 'mass action turnover escape pool', is characterized by mass action turnover of smaller ruminated particles that are more fermentatively spent, and less buoyant particles. This is the pool which primarily constrained escape of the ruminated smaller and fermentatively spent faecal small particles in the present study. Also, it is the terminal pool from which particles escape via mass action turnover. Jessop \& Illius (1999) have demostrated that incorporation of buoyancy mechanisms yields results identical to the $\mathrm{G} 2 \rightarrow \mathrm{G} 1 \rightarrow \delta \rightarrow \mathrm{O}$ model.

In compartmental modelling, a mixing compartment is defined as the volume in which influx is instantaneously mixed. Model assumptions of instantaneous mixing and steady-state conditions are inappropriate for the relatively slow and incomplete mixing of input with total ruminal digesta. Instantaneous and perfect mixing within each compartment is assumed by models having exponentially distributed residence times such as those proposed by Blaxter et al. (1956), Brandt \& Thacker (1958), Grovum \& Williams (1973), Milne et al. (1978), Faichney \& Boston (1983), Dhanoa et al. (1985) and France et al. (1985). Incorporating an age-dependent distribution of residence times for the initial entry compartment provides some accommodations for the slow, imperfect and incomplete mixing processes. Thus, the term 'pool' (Jacquez, 1996) should replace 'compartment' to be more descriptive of the less discretely defined and commingled particles that are defined here by their order of residence time distributions in contrast to discrete physical compartments.

Because the two functionally defined pools (GN and G1) are commingled, they cannot be resolved by sampling ruminal digesta but must be estimated by sampling the efflux from the commingled pools (i.e. abomasal or duodenal digesta).

\section{Relations to other reports}

The conclusion here presented that the ruminal digesta is the site of two mixing pools is contrary to interpretations of Grovum \& Williams (1973), Faichney \& Boston (1983) and Faichney (1984). These workers suggested the caecumproximal colon as a major site of digesta residence time. Such a contrasting interpretation by Grovum \& Williams (1973) appears to be primarily due to their sampling the abomasum beginning $11 \mathrm{~h}$ after injecting markers into the rumen, a delay during which CMRT1 values as observed here ( 9.8 and $10.4 \mathrm{~h}$ for hay and faecal small particles) would have been undetectable. Also, these investigators used solute markers (CrEDTA), loosely bound ${ }^{103} \mathrm{Ru}$-phenanthroline and ionic rare earths that adsorb onto residues from a succession of meals rather than a discrete meal as assumed by the model. In the present experiment, rare earths were selectively bound onto hay or its masticated residues. Any unbound marker, marker bound to feed residue sites having a binding affinity less than acetate, or marker displaceable by protons at a $\mathrm{pH}$ equal to or greater than $4 \cdot 1$, was removed by the pre-wash with $\mathrm{pH} 4.5$ buffer (Ellis \& Beever, 1984). Using related techniques, others have observed a two-compartment pattern for rare-earth particles leaving the rumen (Ellis et al. 1979, 1984a, 1994; Pond et al. 1988) and appearing in the abomasum or duodenum (Faichney \& Boston, 1983; Ellis et al. 1984a, 1994; Pond et al. 1988). It might be suggested that digesta flow in sheep differs from that in cattle. However, in a slaughter experiment Wylie (1987) observed that $95-97 \%$ of the mass and residence time for indigestible neutral-detergent fibre resided in the rumen and reticulum.

Increasing orders of GN will partition increasing portions of residence time to the age-dependent compartment at the expense of the transit time (Matis, 1972). Thus, transit time estimated by the $\mathrm{G} 3 \rightarrow \mathrm{G} 1 \rightarrow \tau \rightarrow \mathrm{O}$ model will be some 2 $3 \mathrm{~h}$ less (Ellis et al. 1994) than that estimated using exponential, age-independent compartment models (essentially 
Table 7. Distribution of compartmental mean residence time in mixing system (CMRTS) and time delay $(\tau)$ for flow of hay particles through segments of the gastrointestinal tract of mature cattle

\begin{tabular}{|c|c|c|c|c|}
\hline \multirow[b]{2}{*}{ Estimate } & \multirow{2}{*}{$\frac{\text { CMRTS }}{\mathrm{h}}$} & \multirow{2}{*}{$\frac{\tau}{\% \text { summated total }}$} & \multirow[b]{2}{*}{$\mathrm{h}$} & \multirow[b]{2}{*}{$\%$ summated total } \\
\hline & & & & \\
\hline 1. Diet to ascending duodenum & $46 \cdot 6$ & & 3.0 & \\
\hline 2. Cranial abomasum to ascending duodenum & $1 \cdot 1$ & & 0.5 & \\
\hline 3. Ruminal digesta + omasum (1-2) & 45.5 & 94.2 & 2.5 & $25 \cdot 6$ \\
\hline 4. Ascending duodenum to faeces $(6-1)$ & $2 \cdot 8$ & 5.8 & $7 \cdot 3$ & 74.4 \\
\hline 5. Summated total for components $(2+3+4)$ & $49 \cdot 3$ & $100 \cdot 0$ & $12 \cdot 1$ & $100 \cdot 0$ \\
\hline 6. Diet to faeces, gastrointestinal ${ }^{*}$ & $47 \cdot 3$ & & $11 \cdot 0$ & \\
\hline
\end{tabular}

*Observed mean from Table 6.

$\mathrm{G} 1 \rightarrow \mathrm{G} 1 \rightarrow \tau \rightarrow \mathrm{O}$ ) such as those of Blaxter et al. (1956), Brandt \& Thacker (1958), Grovum \& Williams (1973), Milne et al. (1978) and Faichney \& Boston (1983).

\section{Gastric v. post-gastric residence time in cattle}

The present results are summarized in Table 7 to express the distribution of CMRTS and time delays. This summary indicates that CMRTS due to mixing flow in the ruminalomasal digesta represented $94.2 \%$ of that for the entire gastrointestinal tract. The time delay (passage lag time) represented $25 \%$ of the time delay between normal ingestion of hay and its first detection in the faeces. The mean post-abomasal transit time of $9.8 \mathrm{~h}$ is of similar magnitude to intestinal transit times summarized for cattle by Warner (1981) using other methods. Estimates for post-gastric transit time observed here for all materials are similar to those reported for pregnant ewes by Faichney \& White (1988).

The present results indicate post-ruminal mixing pools to be relatively minor in cattle. Therefore, the rate parameters $\lambda_{1}$ and $k_{2}$ may be estimated with reasonable accuracy from sampling faeces.

\section{Implications}

(1) As a consequence of two mixing pools in ruminal digesta, the mean ruminal residence time is considerably longer than predicted from commonly used models assuming a single, mass action dilution turnover-escape compartment. Huhtanen \& Vanhatalo (1997) have recently emphasized the need to include ruminal residence time in addition to escape turnover in order to account for the observed extent of digestion of fibre. For more digestible diets fed to lactating dairy cattle, underestimation of ruminal residence time may be greater than the $125 \%$ observed here.

(2) Because the two mixing pools are physically commingled in ruminal digesta, residence time due to the two mixing pools cannot be estimated by sampling ruminal digesta, as is commonly assumed. Estimation should involve a rareearth-marked feed ingested as a single meal with subsequent sampling of digesta at the most proximal ruminal efflux site or, possibly, the faeces.

(3) Small samples of feed residues inserted into the ruminal digesta may not mimic the flow of normally ingested feed.
(4) Further data supporting a generalization of the dominance of ruminal residence time reported here would allow use of more accessible faecal sampling to estimate ruminal residence required for feed evaluation systems based on kinetic models.

\section{References}

Blaxter KL, Graham NM \& Wainman NM (1956) Some observations on the digestibility of food by sheep, and on related problems. British Journal of Nutrition 10, 69-91.

Brandt CS \& Thacker EJ (1958) A concept of rate of food passage through the gastro-intestinal tract. Journal of Animal Science 17, 218-223.

Dhanoa MS, Siddons RC, France J \& Gale DL (1985) A multicompartment model to describe marker excretion patterns in ruminant faeces. British Journal of Nutrition 53, 663-671.

Ellis WC, Baily EM \& Taylor CA (1984a) A silicone esophageal cannula: it's surgical installation and use in research with grazing cattle, sheep or goats. Journal of Animal Science 59, 204-209.

Ellis WC \& Beever DE (1984) Methods for binding rare earths to specific feed particles. In Techniques in Particle Size Analysis of Feed and Digesta in Ruminants, pp. 154-165 [PM Kennedy, editor]. Edmonton: Canadian Society of Animal Science.

Ellis WC, Kennedy P \& Matis JH (1991) Passage and digestion of plant tissue fragments in herbivores. In Proceedings of the $3 \mathrm{rd}$ International Symposium on the Nutrition of Herbivores, pp. 227-236 [YW Ho, HK Wong, N Abdullah and ZA Tajuddin, editors]. Kuala Lumpur: Malaysian Society of Animal Production and Vinlin Press.

Ellis WC, Matis JH, Hill TM \& Murphy MR (1994) Chapter 17. Methodology for estimating digestion and passage kinetics of forages. In Forage Quality, Evaluation, and Utilization, pp. 682-756 [GC Fahey Jr, editor]. Madison, WI: American Society of Agronomy, Inc.

Ellis WC, Matis JH \& Lascano C (1979) Quantitating ruminal turnover. Federation Proceedings 38, 2702-2706.

Ellis WC, Matis JH, Pond KR, Lascano CE \& Telford JP (1984b) Dietary influences on flow rate and digestive capacity. In Herbivore Nutrition in the Subtropics and Tropics, pp. 269293 [FMC Gilchrist and RI Mackie, editors]. Craighall: The Science Press.

Ellis WC, Poppi DP, Matis JH, Lippke H, Hill TH \& Rouquette FH Jr (1999) Dietary-digestive-metabolic interactions determining the nutritive potential of ruminant diets. In Nutritional Ecology of Herbivores. Proceedings of the Vth International Symposium on the Nutrition of Herbivores, pp. 423-480 [HG Jung and GC Fahey Jr, editors]. Savoy, IL: American Society of Animal Science.

Faichney GJ (1984) The kinetics of particulate matter in the rumen. 
In Control of Digestion and Metabolism in Ruminants, pp. 173195 [LP Milligan, WL Grovum and A Dobson, editors]. Englewood Cliffs, NJ: Prentice-Hall.

Faichney GJ \& Boston RC (1983) Interpretation of faecal excretion patterns of solute and particle markers introduced into the rumen of sheep. Journal of Agricultural Science (Cambridge) 101, $575-581$.

Faichney GJ, Poncet C \& Boston RC (1989) Passage of internal and external markers of particulate matter through the rumen of sheep. Reproduction, Nutrition, Development 29, 325-339.

Faichney GJ \& White GA (1988) Rates of passage of solutes, microbes and particulate matter through the gastro-intestinal tract of ewes fed at a constant rate throughout gestation. Australian Journal of Agricultural Research 39, 481-492.

France J, Thornley JHM, Dhanoa MS \& Siddons RC (1985) On the mathematics of digesta flow kinetics. Journal of Theoretical Biology 113, 743-758.

Grovum WL \& Williams VJ (1973) Rate of passage of digesta in sheep. 4. Passage of marker through the alimentary tract and the biological relevance of rate-constraints derived from the changes in concentration of marker in the faeces. British Journal of Nutrition 30, 313-329.

Huhtanen P \& Vanhatalo A (1997) Ruminal and total plant cellwall digestibility estimated by a combined in situ method utilizing mathematical models. British Journal of Nutrition $\mathbf{7 8}$, 583-598.

Jacquez JA (1996) Compartmental Analysis in Biology and Medicine, 3rd ed. Ann Arbor, MI: Bio Medware.

Jessop NS \& Illius AW (1999) Modeling the influence of buoyancy on particle dynamics in the foregut of ruminants. In Nutritional Ecology of Herbivores: Posters, Plenary Discussions and Papers presented at Satellite Symposia and Seminar held in conjunction with the Vth Symposium on the Nutrition of Herbivores, San Antonio, TX, April 10-16, 1999. CD-ROM available from WC Ellis, Department of Animal Science, Texas A \& M University, TX 77843. Can be viewed online at: http://cnrit. tamu.edu/conf/isnh/post-online/post0056/

Luginbuhl JM, Pond KR \& Burns JC (1994) Whole-tract digesta kinetics and comparison of techniques for the estimation of fecal output in steers fed coastal bermudagrass hay at four levels of intake. Journal of Animal Science 72, 201-211.
Matis JH (1972) Gamma time-dependency in Blaxter's compartmental model. Biometrics 28, 597-602.

Matis JH, Wehrly TE \& Ellis WC (1989) Some generalized stochastic compartmental models for digesta flow. Biometrics 45, 703-720.

Milne JA, MacRae JC, Spence AM \& Wilson S (1978) A comparison of the voluntary intake and digestion of a range of forages at different times of the year by the sheep and the red deer (Cervus elaphus). British Journal of Nutrition 40, 347-357.

Pond KR, Ellis WC, James WD \& Deswysen AG (1985) Analysis of multiple markers in nutrition research. Journal of Dairy Science 68, 745-750.

Pond KR, Ellis WC, Matis JH, Sutton JD, Bishop C \& Ferreiro HH (1988) Compartmental models for estimating attributes of digesta flow in cattle. British Journal of Nutrition 60, 571-595.

Pond KR, Ellis WC, Matis JH \& Deswysen AG (1989) Passage of chromium mordanted and rare earth labeled fiber: time of dosing kinetics. Journal of Animal Science 67, 1020-1028.

Seber GAF \& Wild CJ (1989) Nonlinear Regression, p. 110. New York, NY: John Wiley.

Sutherland TM (1986) Particle separation in the forestomach of sheep. In Aspects of Digestive Physiology in Ruminants, pp. 4373 [A Dobson and MH Dobson, editors]. Ithaca, NY: Cornell University Press.

Vega A \& Poppi DP (1997) Extent of digestion and rumen condition as factors affecting passage of liquid and digesta particles in sheep. Journal of Agricultural Science (Cambridge) 128, 207-215.

Warner ACI (1981) Rate of passage of digesta through the gut of mammals and birds. Nutrition Abstracts and Reviews 51, 789820.

Winer BJ (1971) Statistical Principles in Experimental Design, 2nd ed., pp. 261-308. New York, NY: McGraw Hill Book Company.

Wylie MJ (1987) The flow of feed residues through the gastrointestinal tract of ruminants. $\mathrm{PhD}$ Thesis, Texas $\mathrm{A} \& \mathrm{M}$ University, Texas, USA.

Wylie MJ, Ellis WC \& Matis JH (1986) Validity of rare earths as flow markers for undigested feed residues. Journal of Animal Science 63, Suppl. 1, 5. 